\title{
Sterilization of PMMA microfluidic chips by various techniques and investigation of material characteristics
}

\author{
Cansu Yavuz a , Samad Nadimi Bavil Oliaei ${ }^{b}$, Barbaros Cetin ${ }^{c}$, Ozlem Yesil-Celiktas ${ }^{a}, *$ \\ a Novel Fluidic Technologies and Applications Group, Department of Bioengineering, Faculty of Engineering, Ege University, 35100 Bornova, Izmir, Turkey \\ ${ }^{\mathrm{b}}$ Microsystem Design and Manufacturing Center, Mechanical Engineering Department, Ihsan Dogramacl Bilkent University, 06800 Ankara, Turkey \\ ${ }^{\mathrm{c}}$ Microfluidics \& Lab-on-a-chip Research Group, Mechanical Engineering Department, Ihsan Dogramacı Bilkent University, 06800 Ankara, Turkey
}

\section{A R T I C L E I N F O}

\section{Article history:}

Received 11 February 2015

Received in revised form 28 August 2015

Accepted 28 August 2015

Available online 7 September 2015

\section{Keywords:}

Microfluidic device

Microchip

PMMA

Material

Sterilization

Supercritical $\mathrm{CO}_{2}$

\begin{abstract}
A B S T R A C T
The sterilization of microfluidic chips is a vital step of the fabrication process prior to the customer use in biomedical applications. The aim of this study was to analyze the influence of different sterilization techniques and to compare the characteristics of the material before and after sterilization of polymethylmethacrylate (PMMA) microchips. For this, supercritical carbon dioxide $\left(\mathrm{SC}-\mathrm{CO}_{2}\right)$ along with standard sterilization methods such as ultraviolet (UV), heat (autoclaving), ethylene oxide (EtO) and hydrogen peroxide $\left(\mathrm{H}_{2} \mathrm{O}_{2}\right)$ were applied. The treated microchips were analyzed by Scanning Electron Microscopy, Differential Scanning Calorimetry, Fourier Transform Infrared Spectroscopy and Laser Scanning Microscopy in order to ascertain any changes in the chemical structure and surface morphology. The optimum sterilization parameters for $\mathrm{SC}-\mathrm{CO}_{2}$ were elicited as 120 bar, $40{ }^{\circ} \mathrm{C}$ and 60 min which provided complete sterility and did not alter the main properties of the polymer along with EtO and $\mathrm{H}_{2} \mathrm{O}_{2}$ sterilizations unlike heat and UV treatments. However, surface roughness and microchannel profiles were negatively affected. Although complete sterility was achieved, each protocol has its own strengths and weaknesses.
\end{abstract}

(ㄷ) 2015 Elsevier B.V. All rights reserved.

\section{Introduction}

In the past decade, the application of microfluidic technology has grown rapidly in life sciences [1,2]. Recent developments in microfluidics revealed some functions that is included in synthesis and analysis of chemical and biological materials such as genes and proteins, drug delivery, medical diagnostics, cell culture, understanding cell behavior and cell-handling [3,4]. Microchips have several advantages such as fast screening of parameters, rapid mass and heat transfer, low reagent consumption, small and controlled microenvironments and reproducibility [5]. The materials used for construction of microreactors are of prime importance and vary based on the targeted application. Polymethylmethacrylate (PMMA) is commercially the most important member of a range of acrylic materials and used primarily in plastic applications due to excellent mechanical and chemical properties [6]. As PMMA is disposable, biocompatible, transparent, impermeable to air, effective to fabricate and suitable for mass fabrication, it is preferred as

\footnotetext{
* Corresponding author.

E-mail addresses: ozlem.yesil.celiktas@ege.edu.tr, ozlemyesil@gmail.com (O. Yesil-Celiktas).
}

a polymeric material in the fabrication of microfluidic devices $[2,4]$ and medical applications [6]. Applications of microfluidic systems based on cell and tissue culture are now emerging as physiologically relevant microenvironments can be fabricated by in vitro cell culture. Microfluidic cell culture poses elicitation of specific sterilization requirements. Current methods of sterilization for the removal of microorganisms from medical devices include steam autoclaving, ethylene oxide treatment, UV and hydrogen peroxide treatment [7-9]. However, the techniques have obvious drawbacks and cannot be applied for sterilization of some materials such as polymeric medical devices and heat-sensitive biomaterials [8-10].

Sterilization with supercritical carbon dioxide $\left(\mathrm{SC}-\mathrm{CO}_{2}\right)$ is reported as an alternative technique for sterilization of biological pathogens [7]. Carbon dioxide has many features such as low critical temperature and pressure, is inexpensive, non-toxic, inert and non-flammable. Moreover, it can be completely removed from the material that is processed with $\mathrm{SC}-\mathrm{CO}_{2}[11-13]$. Steam sterilization is the most common technique because of its low cost, effectiveness, easiness to process and not producing toxic compounds [14]. However, steam sterilization operates at $121^{\circ} \mathrm{C}$ so heat-sensitive materials will be damaged or destroyed. Therefore, UV and ethylene oxide sterilization can be applied to heat-labile materials [10]. Ethylene oxide is flammable and toxic, ethylene oxide residues on 


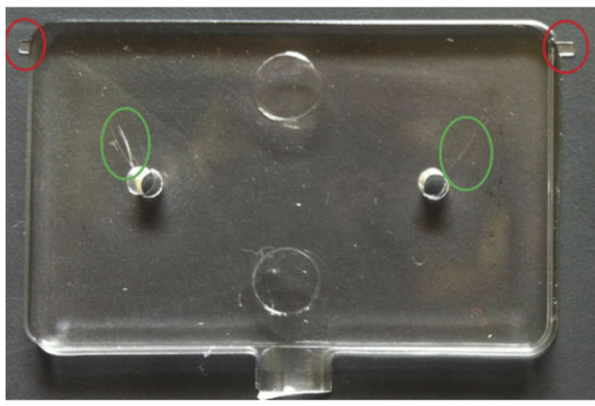

(A)

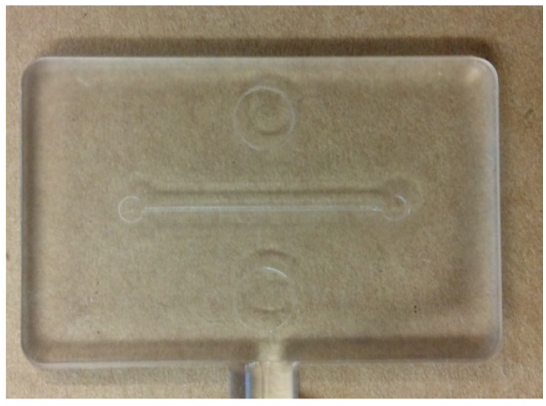

(B)

Fig. 1. Injected parts of PMMA (A) and the single channel microfluidic chip (B).

the surfaces can cause hemolysis and become carcinogen $[7,10]$. In addition, the sterilization period is very long [8]. Hydrogen peroxide is not toxic and it has a highly microbicidal effectiveness against a broad spectrum of microorganisms [15]. Hydrogen peroxide plasma produces large amounts of free radicals in order to achieve sterilization. These free radicals may adversely affect the chemistry of the sterilized material [9]. This technique is safe for the human body and harmless to the environment [8]. UV radiation has the DNA as main target for microorganisms elimination [14].

In this study, supercritical $\mathrm{CO}_{2}$ sterilization of PMMA microchip was investigated and compared with those of standard sterilization techniques both in terms of sterility and possible changes in the characteristics of the polymeric material. Scanning Electron Microscopy (SEM), Differential Scanning Calorimetry (DSC) and Fourier Transform Infrared Spectroscopy (FTIR) were used to determine physical and chemical properties of material after sterilization. Although, various studies were reported in regards to terminal sterilization of bacterial endospores $[9,16]$ and microbial inactivation using high pressure carbon dioxide [17-19], sterilization of a microfluidic chip using supercritical carbon dioxide has not been presented before to the best of our knowledge.

\section{Materials and methods}

\subsection{Materials}

Tryptic Soy Broth (TSB) and Thioglycollate Broth (TGB) were obtained from Sigma. Sterilization paper was purchased from Tyvek roll and chemical indicator was purchased form Sterrad for hydrogen peroxide treatment. Ethanol was purchased from Merck. Nanopure water used in the analysis was prepared by using in-house nanopure water system (SartoriusArium 611, SartoriusStedim, Gottingen, Germany). Sterile cabin and incubator were used for incubation under steril conditions (Jauan-MSC12/Class II, Forma series II-Hepa class 100 respectively). Ethylene oxide sterilizator was used (Axis AX-60 \& AX135 series) and UV sterilizator was used (GOLDTERM, UV 1679 model).

\subsection{Fabrication of microfluidic chips}

The PMMA microchip was fabricated using injection molding process, where the mold was fabricated out of blank (unmachined) mold by using the high precision CNC system (Deckhel Maho DMU 50) at Bilkent University Micro System Design and Manufacturing Center. The mold material was chosen as the stainless mold steel CK - 50 AISI 1.1050. Four-tooth coated carbide tools were preferred in the machining process and a $5^{\circ}$ draft angle was introduced at the side-walls of the microchannels and the mold cavity for the ease of demolding. During the machining of the mold, firstly, the runner, gate and mold cavities were roughly machined and then the base and side-walls of the cavity were machined with $0.5 \mathrm{~mm}$ tolerance. After the machining, a surface finish operation was performed by using a grinding machine and a grinding paste in order to increase the surface quality. Lengths of the microchannels were $20 \mathrm{~mm}$ and each has a width and a depth of $240 \mu \mathrm{m}$. Evonik plexiglas 6N (PMMA-Acrylics) was used as the material. The injection was performed using a plastic injection molding machine with a maximum injection pressure of $90 \mathrm{MPa}$ [20]. The injected parts can be seen in Fig. 1.

\section{Sterilization}

\subsection{Supercritical $\mathrm{CO}_{2}$ sterilization}

Supercritical $\mathrm{CO}_{2}$ sterilization was carried out using SFE-100 System (Thar Instruments, Inc., UK, 2006). Microchips were packed in sterilized cartridges and placed into the reaction chamber. Operating parameters for sterilization were temperature $(25,40,50$ and $\left.60^{\circ} \mathrm{C}\right)$, pressure $(70,100,120,150$ and 250 bar $)$ and time $(30,45$, 60 and $90 \mathrm{~min}$ ). Sterilizations were performed under automated control of temperature and pressure. The process was started by reaching the set temperature and pressure values. Flow rate was $10 \mathrm{~g} / \mathrm{min}$ for all sterilization processes. At the end of sterilization process, the valve of $\mathrm{CO}_{2}$ tube was sealed off for depressurization and releasing $\mathrm{CO}_{2}$ from the system was approximately $45 \mathrm{~min}$.

\subsection{Heat sterilization}

Heat sterilization or autoclaving is a relatively simple process that exposes the device to saturated steam at $121^{\circ} \mathrm{C}$ for $20 \mathrm{~min}$ at a pressure of $115 \mathrm{kPa}$. The process kills microorganisms by destroying metabolic and structural components essential to their replication.

\subsection{UV sterilization}

For UV radiation, the microchips were exposed to UV light $(254 \mathrm{~nm})$ for $45 \mathrm{~min}$ on each side, totaling up to a treatment of $90 \mathrm{~min}$. Microreactors were placed into petri dishes.

\subsection{Ethylene oxide sterilization}

The ethylene oxide (EtO) sterilization process utilizes EtO which has bactericidal, sporicidal and virucidal effects in nucleic acids causing cell injury or death. In this study, microreactors were exposed the EtO concentration of $5 \mathrm{mg} / \mathrm{ml}$ for $3 \mathrm{~h}$ at $55^{\circ} \mathrm{C}$ and aeration for $12 \mathrm{~h}$. 


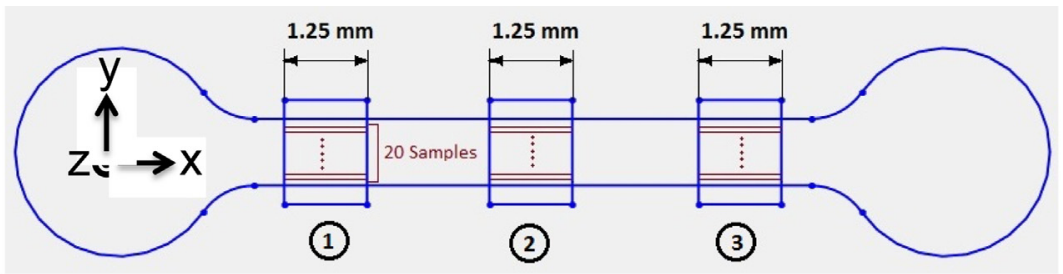

(A)

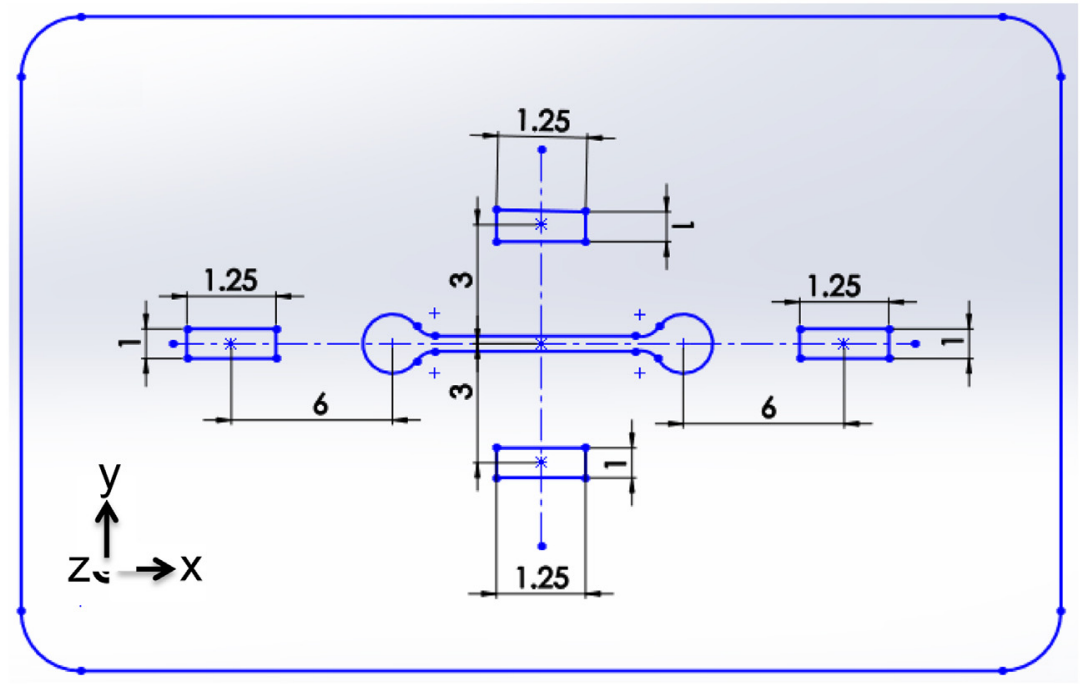

(B)

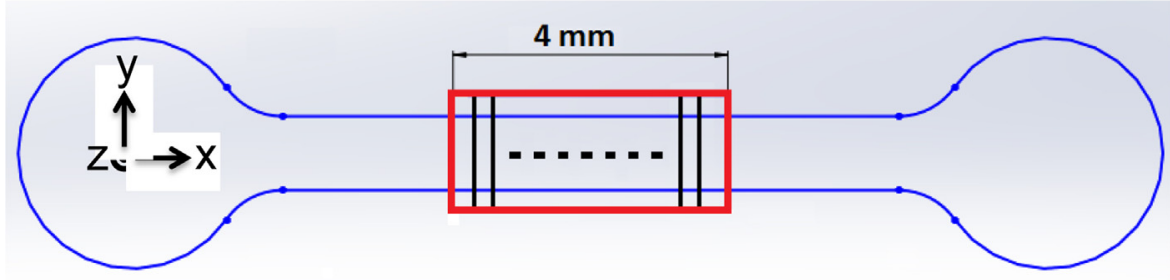

(C)

Fig. 2. Surface roughness measurements on the channel surface (A) and on the part surface (B) along with channel profile measurements (C).

\subsection{Hydrogen peroxide sterilization}

Hydrogen peroxide has bactericidal, virucidal, sporicidal, and fungicidal properties. Although most microbial forms are killed in less than $1 \mathrm{~h}$, it takes hours to eliminate spores. It should be stored in a cool place and protected from the light. The microchips were treated with hydrogen peroxide (HP) for $1 \mathrm{~h}$ and stored at a cool place protected from light for about $48 \mathrm{~h}$.

\subsection{Determination of sterility}

The sterility was determined by incubating the sterilized microchips in tryptic soy broth (TSB) and thioglycollate broth (TGB) to assess the microbiological loads at two different incubation temperatures $\left(27^{\circ} \mathrm{C}\right.$ and $\left.37^{\circ} \mathrm{C}\right)$ for a duration of 7 days. Sterility tests were repeated three times.

\subsection{Characterization}

The sterilized microchips were analyzed using Scanning Electron Microscopy (SEM), Fourier Transform Infrared Spectroscopy
(FTIR) and Differential Scanning Calorimetry (DSC) in order to assess microchannel sterility and possible deformations in PMMA.

\subsubsection{Scanning Electron Microscopy (SEM)}

The microchips were viewed by scanning electron microscope (FEI, Quanta 200 F). The samples were dried under vacuum (1 bar) at room temperature and then sputter-coated with a $10 \mathrm{~nm}$ thick gold layer before imaging (Gatan 682, precision etching coating system)

\subsubsection{Differential Scanning Calorimetry (DSC)}

Thermal behavior of the microchips was measured by differential scanning calorimetry (TA Instruments, Q2000), where the samples were packed into aluminum and DSC sample pans with the lid tightly crimped. Nitrogen was purged at a flow rate of $50 \mathrm{ml} / \mathrm{min}$ and measurements were made in temperature range between 30 and $250^{\circ} \mathrm{C}$ at a heating rate of $10^{\circ} \mathrm{C} / \mathrm{min}$.

\subsubsection{Fourier Transform Infrared Spectroscopy (FTIR)}

Fourier transform infrared spectra of the microchips were recorded from $8000 \mathrm{~cm}^{-1}$ to $200 \mathrm{~cm}^{-1}$ (Bruker VERTEX 70 with Hyperion Scanning Microscope). 


\subsubsection{Surface roughness and profile characteristics}

In order to investigate the effect of different sterilization techniques on surface quality and profile of the microchannels, 3D topography of the channels was obtained using Keyence VK-X100 laser scanning microscope. Arithmetic roughness average $\left(R_{a}\right)$ was used as a measure of surface roughness which is defined as the arithmetic average height of surface irregularities (peaks and valleys) from the mean line within the scanning length. Averaging was performed on the measured surface topography both on the microchannel surface and part (chip) surface. For the measurements on the channel surface, 20 samples with a scanning length of $1.25 \mathrm{~mm}$ at three different locations were measured as depicted in Fig. 2A. For the measurements on the chip surface, 20 samples with a scanning length of $1.25 \mathrm{~mm}$ at four different locations were measured as depicted in Fig. 2B. In order to remove the effect of waviness on measured roughness values, a cut-off filter of $0.25 \mathrm{~mm}$ was applied to the measured roughness profile. The effect of primary surface profile on the roughness was eliminated by applying suitable mathematical (tilt and curvature) corrections.

The average profile of the microchannels was obtained using profile measurements at 100 different locations equally spaced within the area of interest and the illustration of the process is given in Fig. 2C.

\section{Results and discussion}

\subsection{Sterilization techniques applied to microchips}

Optimization of supercritical $\mathrm{CO}_{2}$ sterilization procedure was the core objective of this study. Initially, various pressures ( 70 , $100,120,150$ and 250 bar) from subcritical to supercritical were applied at a flow rate of $10 \mathrm{~g} / \mathrm{min}$ while keeping the temperature and time constant at $40^{\circ} \mathrm{C}$ and $60 \mathrm{~min}$, respectively. Although rapid pressurization/depressurization cycles of $\mathrm{SC}-\mathrm{CO}_{2}$ were reported to cause membrane disruption and cell lysis [21,22], the release of $\mathrm{CO}_{2}$ from the system was kept approximately $45 \mathrm{~min}$ to avoid swelling of the polymer. Subsequent to $\mathrm{SC}-\mathrm{CO}_{2}$ sterilization, treated microchips were incubated in tryptic soy broth and thioglycollate broth at two different temperatures $\left(27^{\circ} \mathrm{C}\right.$ and $\left.37^{\circ} \mathrm{C}\right)$ for about 7 days. Tryptic soy broth and thioglycollate broth was used for determination microbiological loads for aerobic microorganisms and anaerobic microorganisms,respectively [23]. Under these conditions, the experiment at 120 bar revealed the best solution in terms of sterility.

As a second step, various temperatures were tested $(25,40$, 50 and $60^{\circ} \mathrm{C}$ ), whereas the pressure was set to 120 bar and the flow rate to $10 \mathrm{~g} / \mathrm{min}$ while and time was $60 \mathrm{~min}$. Temperatures
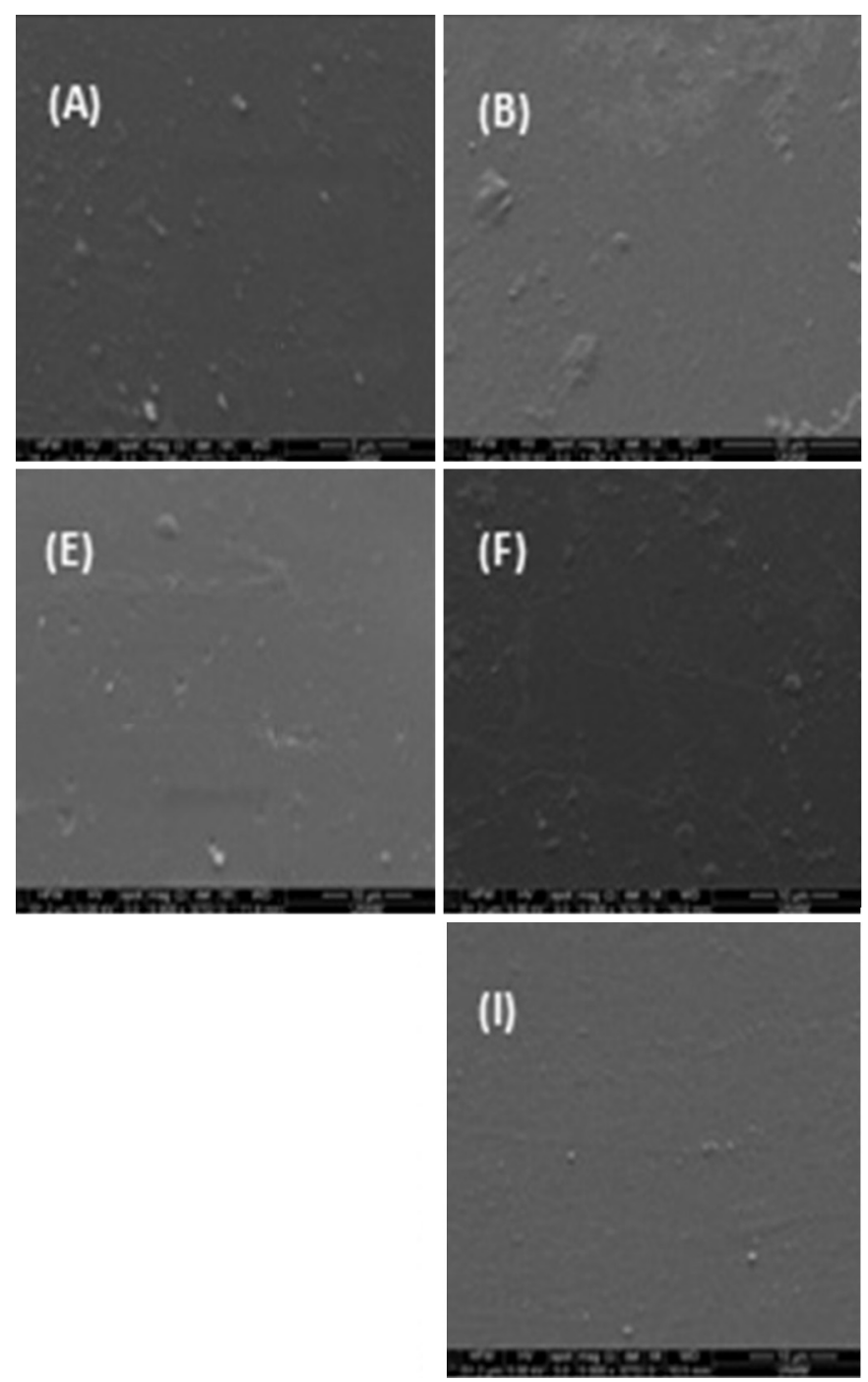
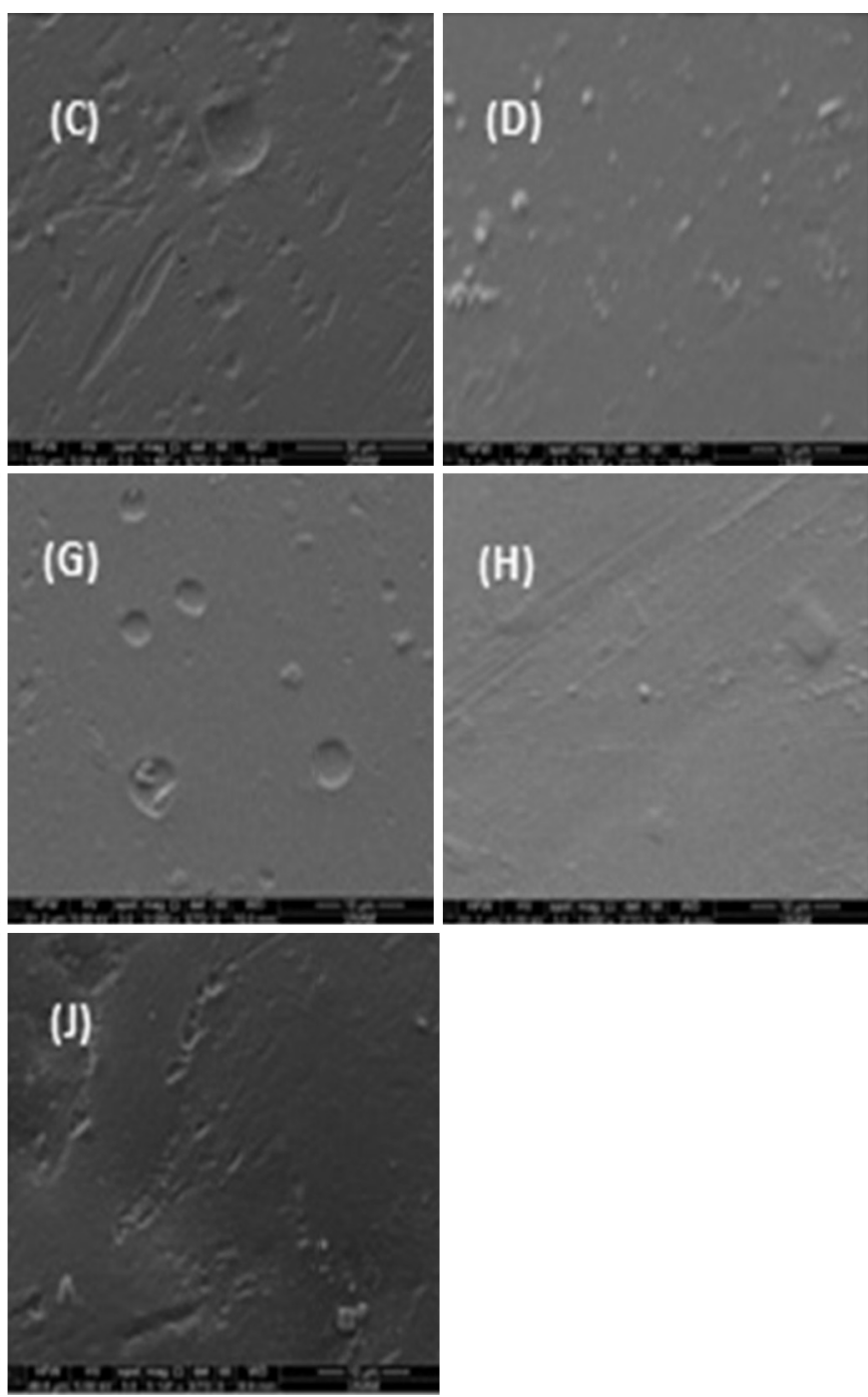

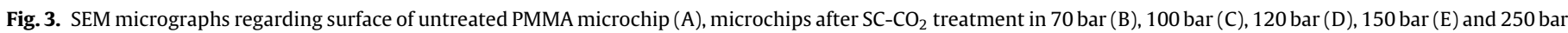
(F) along with microchips after standard sterilization treatments namely, heat (G), ethylene oxide (H), hydrogen peroxide (I) and UV (J). 

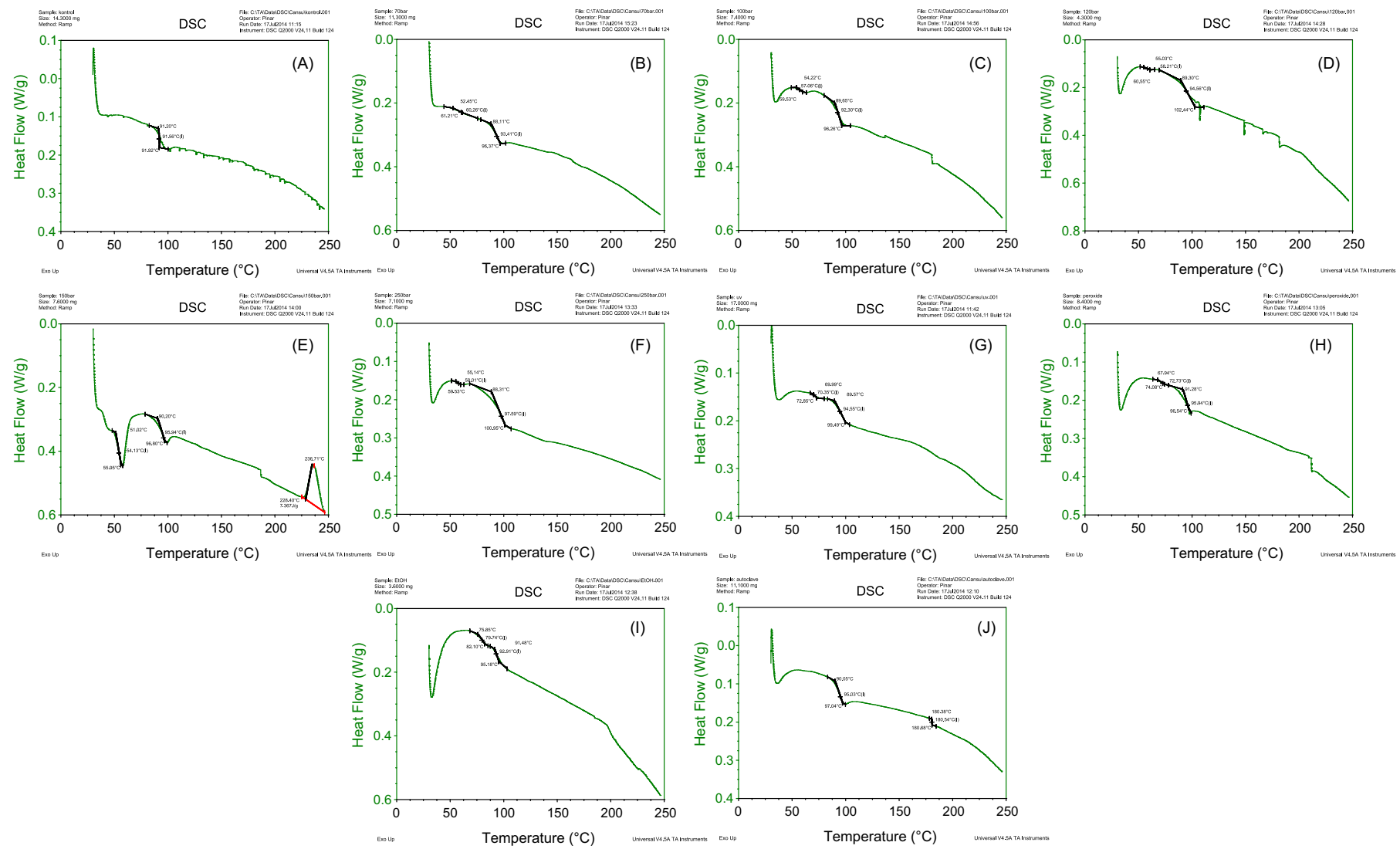

Fig. 4. DSC thermograms of untreated PMMA microchip $(A)$, microchips treated with $\mathrm{SC}-\mathrm{CO}_{2}$ at 70 bar $(\mathrm{B})$
treated with standard techniques namely, $\mathrm{UV}(\mathrm{G})$, hydrogen peroxide $(\mathrm{H})$, ethylene oxide $(\mathrm{I})$ and heat $(\mathrm{J})$.

above $40^{\circ} \mathrm{C}$ along with the pressure changed the transparency of the polymer entirely to opaque. Therefore, the optimum temperature was elicited as $40^{\circ} \mathrm{C}$ which sustained the transparency and the sterility of the microchip. Finally, sterilization time was considered by treating the microchips for $30 \mathrm{~min}, 45 \mathrm{~min}$ and $60 \mathrm{~min}$ while the other parameters were kept constant. Consequently, the sterilization protocol was ascertained to be operated at a pressure of $120 \mathrm{bar}$, a temperature of $40^{\circ} \mathrm{C}$ and a time of $60 \mathrm{~min}$.

Within this study, the microchips were also subjected to saturated steam at $121^{\circ} \mathrm{C}$ for $20 \mathrm{~min}$ by autoclaving, whereas they were exposed to UV light at $254 \mathrm{~nm}$ for $45 \mathrm{~min}$ on each side, totaling up to a treatment of $90 \mathrm{~min}$. As for chemical sterilizations, the chips were treated with hydrogen peroxide and ethylene oxide. Subsequent to sterilization, the same sterility procedure was applied to the treated microchips.

\subsection{Effects of sterilization techniques on material characteristics}

The effects of different sterilization procedures were investigated in terms of material characteristics. The surface morphologies were evaluated using SEM micrographs of untreated and treated PMMA microchips (Fig. 3). Increase in the pressure adversely affected the surface morphology which was particularly observed in PMMA microchips treated at 150 and 250 bar (Fig. 3E and F) appearing as cavities and fractures on the surface, whereas the surfaces of the microchips treated at 70 and 120 bar (Fig. 3B and D) seem as smooth as the untreated. However, sterility could not be achieved with the treatment performed at 70 bar. As for the standard procedures, the surfaces of autoclaved microchips were negatively altered right after the treatment visibly leading to opaque microchips and that was supported by the SEM micrographs (Fig. 3G). Surprisingly, irregularities were also observed in SEM micrographs of UV sterilized microchips (Fig. 3J). On the other hand, both hydrogen peroxide and ethylene oxide treatments revealed smooth surfaces without causing any adverse effects on the material (Fig. 3H and I).

Additionally, DSC thermograms were used to interpret the effect of pressure on glass transition temperature $(\mathrm{Tg})$ of untreated and treated microchips (Fig. 4).

The glass transition temperature, that is, onset of change in the heat capacity was used to describe the motion of the polymer chain segment. PMMA is reported to have a glass transition temperature of about $100-105^{\circ} \mathrm{C}$ [24]. Similar $\mathrm{Tg}$ values were obtained for the microchips treated with heat, UV, hydrogen peroxide and ethylene oxide being little higher than $\mathrm{Tg}$ of untreated microchip which was $91.56^{\circ} \mathrm{C}$. Considering supercritical $\mathrm{CO}_{2}$ treated microchips, increase in pressure from 70 to 250 bar has not resulted in a significant difference in $\mathrm{Tg}$ values (Fig. 4B-F). In a study, at lower pressures up to about $400 \mathrm{bar}, \mathrm{Tg}$ decreased linearly with pressure [25] as a wide range of pressure was applied. Basically, four types of glass transition behavior of polymers in compressed gases were reported using a lattice theory and the Gibbs-Di Marzio criterion which were interpreted as a function of three factors: the solubility of gases in polymer, the flexibility of the polymer and the critical temperature of the fluid. It has been stated that the glass transition behavior of PMMA in $\mathrm{CO}_{2}$ showed a retrograde vitrification which corresponded to Type IV [24]. $\mathrm{CO}_{2}$ induces polymer plasticization causing an increase of the inter-chain distances as well as of the degree of chains-segmental mobility and increase the diffusion rates in the polymer matrix [26]. Appearance of Type IV behavior in 

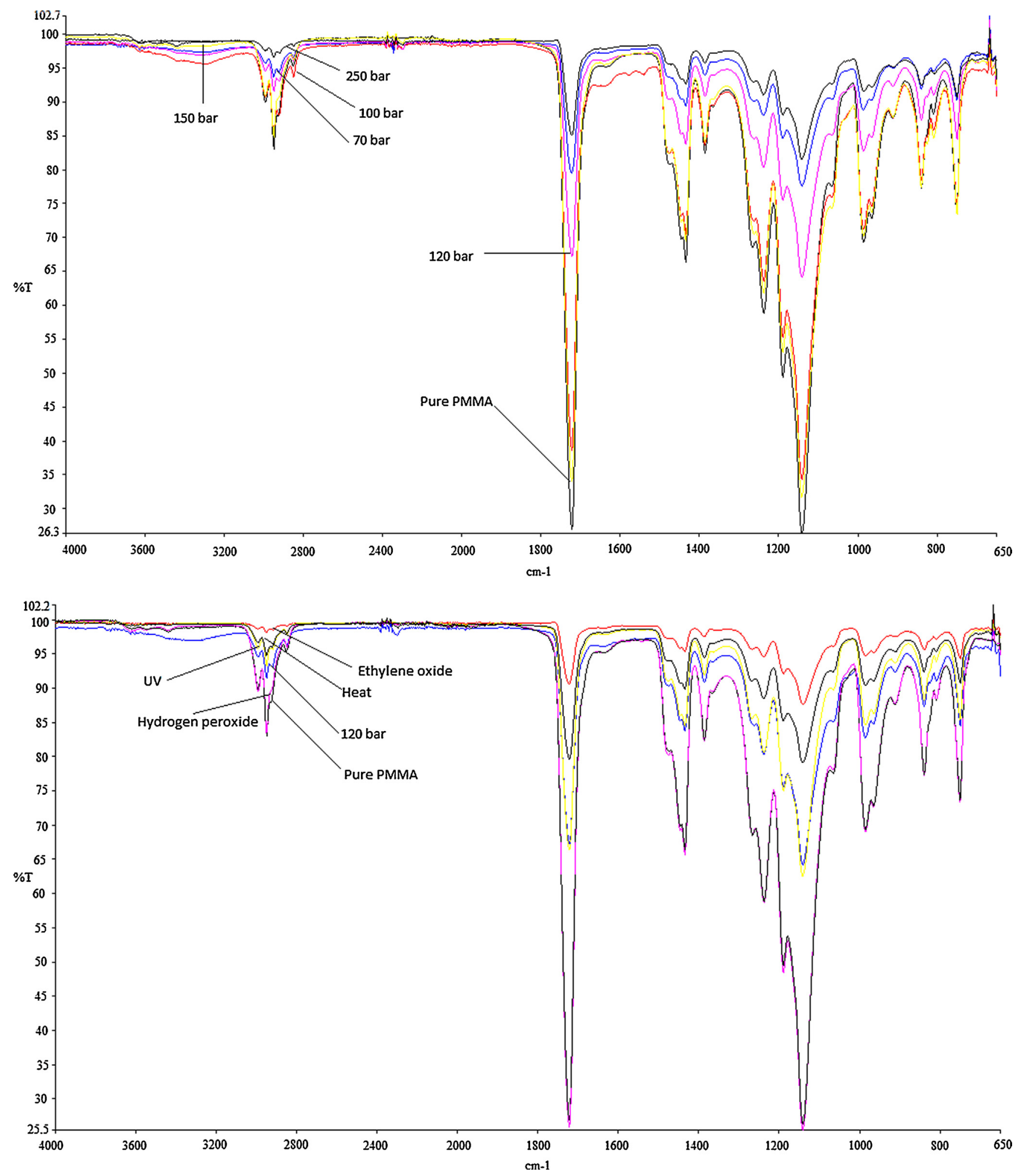

Fig. 5. FTIR spectra of untreated PMMA microchip and microchips after $\mathrm{SC}-\mathrm{CO}_{2}$ and standard sterilization treatments.

PMMA with $\mathrm{CO}_{2}$ strongly suggests that sorption of $\mathrm{CO}_{2}$ into PMMA is high. Indeed, the treatments at 150 and 250 bar visually led to opaque PMMA microchips.

The FTIR spectra of PMMA confirmed the presence of different bonds in the structure (Fig. 5). Polymethacrylates give a series of characteristic infrared bands at 2950,1722, 1435, 1386, $1238,1190,1142,986,840,810$ and $751 \mathrm{~cm}^{-1}[6,27,28]$. Untreated
PMMA showed a band at $2950 \mathrm{~cm}^{-1}$ assigned to $\mathrm{C}-\mathrm{H}$ stretching. The presence of $\mathrm{C}=\mathrm{O}$ bending bonds was seen between $750 \mathrm{~cm}^{-1}$ and $810 \mathrm{~cm}^{-1}$. C $-\mathrm{C}$ stretching bonds were observed between $900 \mathrm{~cm}^{-1}$ and $1000 \mathrm{~cm}^{-1}$, whereas $\mathrm{C}-\mathrm{O}$ stretching mode was seen at $1238 \mathrm{~cm}^{-1}$. Additionally, $\mathrm{CH}_{3}$ deformation was observed between $1300 \mathrm{~cm}^{-1}$ and $1500 \mathrm{~cm}^{-1}$. The peak at $1730 \mathrm{~cm}^{-1}$ indicated $\mathrm{C}=\mathrm{O}$ skeletal mode and the peak between $3000 \mathrm{~cm}^{-1}$ and 


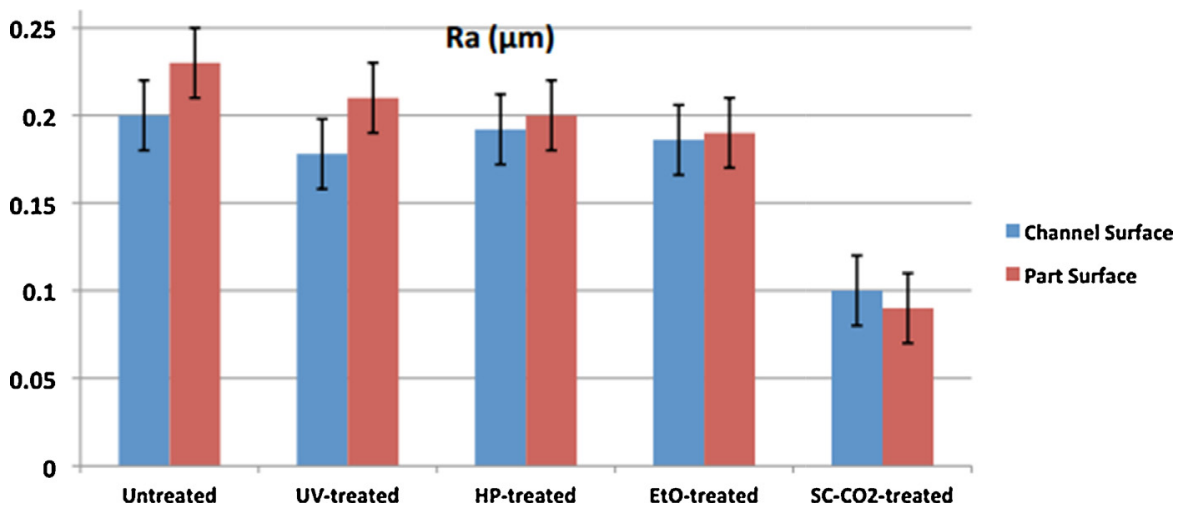

Fig. 6. Average surface roughness.

$4000 \mathrm{~cm}^{-1}$ was related to the $\mathrm{O}-\mathrm{H}$ vibrations. The fingerprint region of PMMA is between 600 and $1400 \mathrm{~cm}^{-1}$ range, which represents the region where most of the bending vibrations occur and provide information about molecule characteristic. Although all spectra revealed similar peaks in regards to different sterilization techniques, the transmittance values for each treatment varied in regards to absorption of the IR radiation. But formation of new bands was not observed indicating that no significant chemical changes occurred in structure of the materials.

Apart from characterization techniques such as SEM, DSC and FTIR, surface roughness and possible changes in channel profiles were investigated as well. The measured roughness values for different sterilized samples were compared to that of the untreated case. As seen from the depiction (Fig. 6), each sterilization technique reduced the surface roughness both on the channel and surface of the chips which will be referred as part. However, the reduction is less than $20 \%$ except for the SC- $\mathrm{CO}_{2}$ treatment. Overall, $\mathrm{HP}$ and EtO treatments exhibited more prominent effects on part surface than on channel surface. UV treatment had the same effect both on the part and channel surface. On the other hand, SC- $\mathrm{CO}_{2}$ treatment significantly influenced the surface roughness and affected the part surface more dominantly. As for the autoclaved microchips,

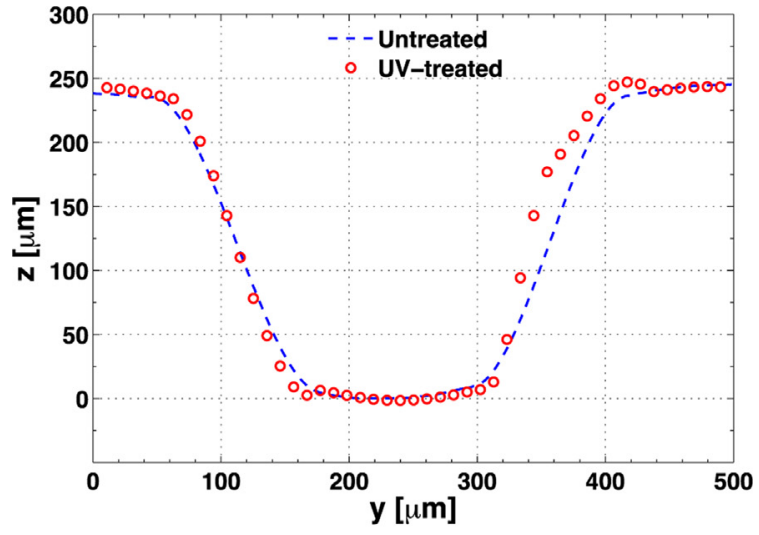

(A)

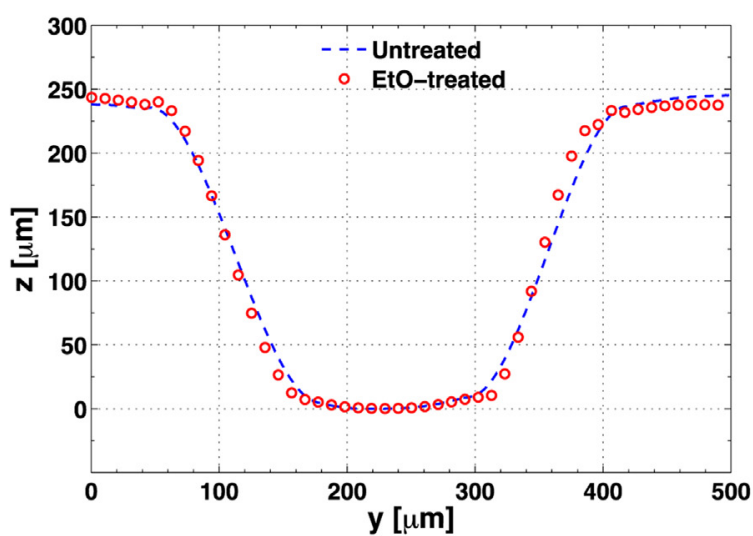

(C)

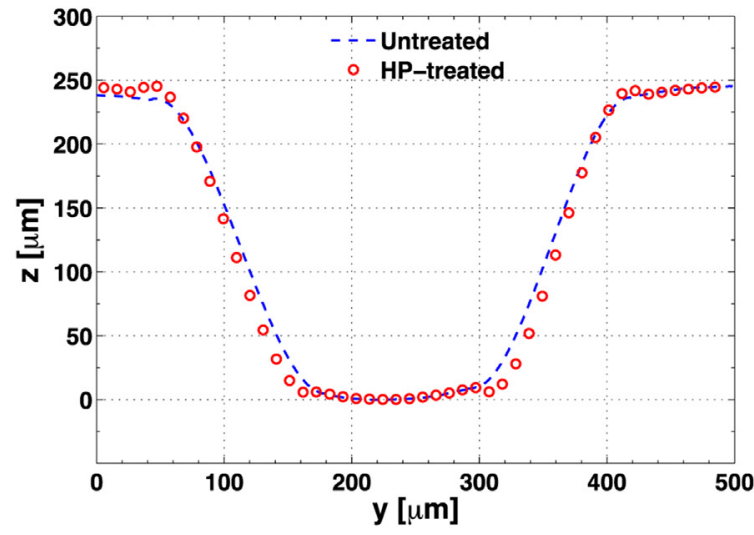

(B)

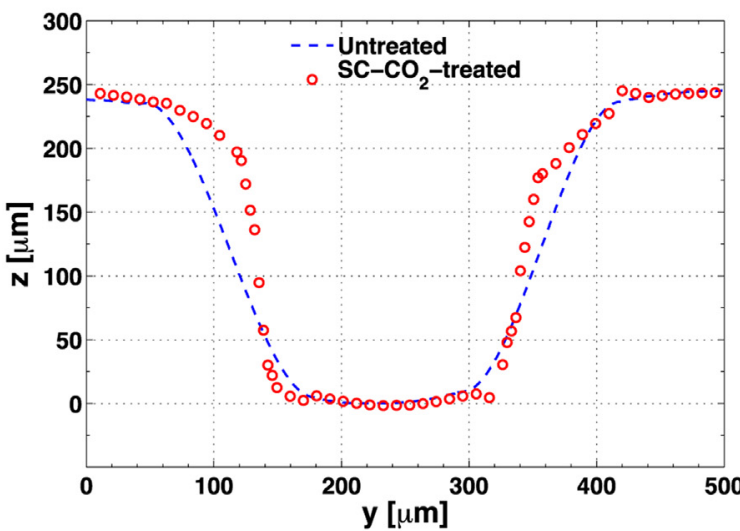

(D)

Fig. 7. Channel profile comparisons of untreated $v s$ UV-treated (A), HP-treated (B), EtO-treated (C) and SC- $\mathrm{CO}_{2}$-treated (D). 
no measurements could be taken due to the fact that the surface and microchannels were badly distorted which was also supported by the SEM micrographs.

Following the surface roughness measurements, the effect of the sterilization techniques on the microchannel profiles was investigated. The average channel profiles for untreated, UV-, HP, EtO-treated and SC- $\mathrm{CO}_{2}$-treated microchannels can be seen in Fig. 7. The effects of the HP- and EtO-treatments in the channel profiles were very minor. However, the channels were totally distorted in autoclaved microchips. As for the $\mathrm{SC}-\mathrm{CO}_{2}$ treated microchips, the treatment exhibited adverse effects on the microchannel profile which is undesired for the microfluidic application, since the distortion of the microchannel would affect the flow inside the microchannel. Regarding UV-treatment, although there is not a significant distortion on the left side-wall, a significant deviation from the untreated profile was observed at the right side-wall.

\section{Conclusion}

In this paper, the focus was on the optimization of supercritical $\mathrm{CO}_{2}$ sterilization and standard sterilization techniques of PMMA microchips while possible changes in material characteristics were determined as well. Optimum parameters of the new sterilization protocol were $120 \mathrm{bar}, 40^{\circ} \mathrm{C}$ and $60 \mathrm{~min}$ which provided complete sterility and did not cause an adverse effect on the main properties of the polymer based on SEM, DSC and FTIR analyses but somehow exhibited adverse effects on the measured surface roughness and microchannel profile. Heat sterilization resulted in opaque structures, whereas chemical sterilization techniques have not affected material characteristics of PMMA but slight variations were observed in terms of surface roughness and channel profile. However that effect was more prominent in UV treated samples especially regarding channel surface and profile. Taken together, sterilization is of prime importance in biomedical applications along with occupational health and safety issues, the current study highlights the strengths and weaknesses of heat, chemical, irradiation and supercritical $\mathrm{CO}_{2}$ treatments.

\section{Acknowledgments}

This work was financially supported by the Research Fund of Ege University (14MUH045). The authors are thankful to AREL at Ege University and National Nanotechnology Research Center at Bilkent University for access to the facilities. The authors also would like to thank Dr. Selim Hanay for his assistance to acquire SEM images.

\section{References}

[1] R. Guillaumenta, A. Erriguiblea, C. Aymonier, S. Marreb, P. Subra-Paternault Numerical simulation of dripping and jetting in supercritical fluids/liquid micro coflows, J. Supercrit. Fluids 81 (2013) 15-22.

[2] H.Y. Tana, W.K. Lokea, N.T. Nguyenb, A reliable method for bonding polydimethylsiloxane (PDMS) to polymethylmethacrylate (PMMA) and its application in micropumps, Sens. Actuators B 151 (2010) 133-139.

[3] J. Moorthy, D.J. Beebe, In situ fabricated porous filters for microsystems, Lab Chip 3 (2003) 62-66.
[4] A. Baraket, N. Zine, M. Lee, J. Bausells, N. Jaffrezic-Renault, F. Bessueille, N. Yaakoubi, A. Errachid, Development of a flexible microfluidic system based on a simple and reproducible sealing process between polymers and poly(dimethylsiloxane), Microelectron. Eng. 111 (2013) 332-338.

[5] O. Yesil-Celiktas, Patenting trends in enzyme related microfluidic applications, Biochem. Eng. J. 92 (2014) 53-62.

[6] M.R.H. Haris, S. Kathiresan, S. Mohan, FT-IR and FT-Raman spectra and normal coordinate analysis of polymethylmethacrylate, Der Pharma Chem. 2 (4) (2010) 316-323.

[7] A. Checinska, I.A. Fruth, T.L. Green, R.L. Crawford, A.J. Paszczynski, Sterilization of biological pathogens using supercritical fluid carbon dioxide containing water and hydrogen peroxide, J. Microbiol. Methods 87 (2011) 70-75.

[8] S. Kitazaki, A. Tanaka, N. Hayashi, Sterilization of narrow tube inner surface using discharge plasma, ozone, and UV light irradiation, Vacuum (2014) 1-4

[9] A. White, D. Burns, T.W. Christensen, Effective terminal sterilization using supercritical carbon dioxide, J. Biotechnol. 123 (2006) 504-515.

[10] J. Zhang, T.A. Davis, M.A. Matthews, M.J. Drews, M. LaBerge, Y.H. An, Sterilization using high-pressure carbon dioxide, J. Supercrit. Fluids 38 (2006) 354-372.

[11] S.K. Luthera, J.J. Schustera, A. Leipertza, A. Braeuera, Microfluidic investigation into mass transfer in compressible multi-phase systems composed of oil, water and carbon dioxide at elevated pressure, J. Supercrit. Fluids 84 (2013) $121-131$

[12] O. Ratcharaka, A. Sane, Surface coating with poly(trifluoroethyl methacrylate) through rapid expansion of supercritical $\mathrm{CO}_{2}$ solutions, J. Supercrit. Fluids 89 (2014) 106-112

[13] I. Pasquali, J.M. Andanson, S.G. Kazarian, R. Bettini, Measurement of $\mathrm{CO}_{2}$ sorption and PEG 1500 swelling by ATR-IR spectroscopy, J. Supercrit. Fluids 45 (2008) 384-390

[14] M.A. de Moraes, R.F. Weska, M.M. Beppu, Effects of sterilization methods on the physical, chemical, and biological properties of silk fibroin membranes, Biomed. Mater. Res. Part B: Appl. Biomater. 102 (2013) 869-876.

[15] P. Kirchner, J. Oberlander, H.P. Suso, G. Rysstad, M. Keusgen, M.J. Schöning, Monitoring the microbicidal effectiveness of gaseous hydrogen peroxide in sterilization processes by means of a calorimetric gas sensor, Food Control 31 (2013) 530-538.

[16] S. Spilimbergo, A. Bertucco, Non-thermal bacteria inactivation with dense $\mathrm{CO}_{2}$, Biotechnol. Bioeng. 84 (2003) 627-638

[17] S. Spilimbergo, N. Elvassore, A. Bertucco, Microbial inactivation by high-pressure, J. Supercrit. Fluids 22 (2002) 55-63.

[18] H.M. Lin, N.J. Cao, L.F. Chen, Anti-microbial effect of pressurized carbon dioxide on Listeria monocytogenes, J. Food Sci. 59 (1994) 657-659.

[19] H.M. Lin, Z. Yang, L.E. Chen, Inactivation of Leuconostoc dextranicum with carbon dioxide under pressure, Chem. Eng. J. (Lausanne) 52B (1993) 29-34.

[20] B. Cetin, A.K. Koska, M. Erdal, Warpage characterization of microchannels fabricated by injection molding, J. Micro- and Nano-Manuf. 3 (2015) 021005

[21] K. Nakamura, A. Enomoto, H. Fukushima, K. Nagai, M. Hakoda, Disruption of microbial cells by the flash discharge of high-pressure carbon dioxide, Biosci. Biotechnol. Biochem. 58 (1994) 1297-1301.

[22] T.P. Castor, G.T. Hong, Critical fluid disruption of microbial cells, in: M. Mc Hugh (Ed.), Proceedings 2nd International Symposium on Supercritical Fluids, 1991, pp. 139-142.

[23] B.M. Sahay, S. Dahake, D.K. Mendiratta, V. Deotale, B. Premendran, P.S Dhande, P. Narang, Bacteriological profile of epidural catheters, JK Sci. J. Med. Educ. Res. 12 (2010) 23-26.

[24] Y. Uosaki, T. Moriyoshi, Glass transition behaviour of poly(methyl metacrylate) in compressed gasses, in: M.H. Manghnani, W.J. Nellis, M.F. Nicol (Eds.), Science and Technology of High Pressure: Proceedings of the AIRAPT-17, vol. 2, Honolulu, Hawaii, 1999, pp. 818-821.

[25] Y.P. Handa, P. Kruus, M. O'Neill, High-pressure calorimetric study of plasticization of poly(methyl methacrylate) by methane, ethylene, and carbon dioxide, J. Polym. Sci. Part B: Polym. Phys. 34 (1996) 2635-2639.

[26] Z. Bayraktar, E. Kiran, Gradient blending of poly(dimethylsiloxane) with polystyrene and polyethylene in supercritical carbon dioxide, J. Supercrit. Fluids 44 (2008) 48-61.

[27] F. Huth, A. Govyadinov, S. Amarie, W. Nuansing, F. Keilmann, R. Hillenbrand, Nano-FTIR absorption of molecular fingerprints at $20 \mathrm{~nm}$ spatial resolution, Nano Lett. 12 (2012) 3973-3978.

[28] E.D. Emmons, R.G. Kraus, S.S. Duvvuri, J.S. Thompson, A.M. Covington, High-pressure infrared absorption spectroscopy of poly(methyl methacrylate), J. Polym. Sci. Part B: Polym. Phys. 45 (2007) 358-367. 